\title{
ASPECTOS MORFOMÉTRICOS COMO SUBSÍDIO AO ESTUDO DA CONDUTIVIDADE HIDRÁULICA E SUSCETIBILIDADE EROSIVA DOS SOLOS
}

\author{
morphometrics aspects as subsidy to the study of the hydraulical \\ conductivity and erosive susceptibility of soils
}

Flávio Alves de Sousa *

Sílvio Carlos Rodrigues**

\begin{abstract}
Resumo
O presente estudo analisa a relação entre condutividade hidráulica dos solos, alimentação do lençol freático e capacidade erosiva dos solos, precisa ter informações sobre os dados morfométricos, pois estes auxiliam na compreensão da dinâmica da água da chuva na bacia. As variáveis utilizadas e apresentadas neste artigo são: Altitude Máxima e Mínima; Amplitude altimétrica (Aa); Altura média (Am); Coeficiente de massividade $(\mathrm{Cm})$; Coeficiente orográfico (Co); Indice de rugosidade (Ir); Coeficiente de manutenção $(\mathrm{Cm})$; Extensão do percurso superficial (Eps); Densidade de Drenagem (Dd); Declividade média. Destacamos também as características das rochas e sua origem e as características topográficas da bacia. A análise dos fatores geomorfológicos foi realizada com base em dados planialtimétricos da bacia, como declividade, hipsometria e também com o uso de Sistema de Informação Geográfica (SIG). As informações geomorfológicas e os dados do SIG auxiliaram na determinação dos parâmetros morfométricos
\end{abstract}

Palavras-chave: Morfométricos, Condutividade, Bacia hidrográfica.

\begin{abstract}
This article result of the study that is being developed in the hydrographic basin on the discharge headboard of Rio dos Bois in the district of Iporá(GO). The study that analyzes the relationship among hydraulic conductivity of the soils, feeding of the groundwater and erosive capacity of soils, needs to have information on the data morphometrics, because these aid in the understanding of dynamics of water of the rain in the basin. The used variables and presented in this healthy article: Maximum and Minimum altitude; altimetric Width (Aa); medium Height (Am); massivity Coefficient (Cm); Orographic Coefficient (Co); rugosity Index (Ir); maintenance Coefficient (Cm); Extension of the superficial course (Eps); Density of Drainage (Dd); medium Steepness. We also detached the characteristics of the rocks and your origin and the topographical characteristics of the basin. The analysis of the geomorphologic factors was accomplished with base in given planialtimetrics of the basin, as steepness, hypsometry and also with the use of System of Geographical Information (SIG). The geomorphologic information's and the data of SIG aided in the determination of the morphometrics parameters.
\end{abstract}

Key words: Morphometrics, Conductivity, Hydrographic basin.

\begin{abstract}
Resumen
Ese artículo es resultante del estúdio que está desarrollándose em la cuenca hidrográfica en la alta cabecera de Rio de los Bois en el distrito de Iporá (GO). El estudio que analiza la relación entre la conductibilidad hidráulica de los suelos, alimentacion del agua subterranea y capacidad de erosion de los suelos, necesita tener informaciones sobre los datos morfométricos, porque éstos ayudan en la comprensión de la dinâmica da agua de la lluvia em la cuenca. Las variables usadas y presentadas en ese articulo son: la altitud maxima y mínima; amplitud altimétrica (Aa); altura média (Am); El coeficiente del massividad ( $\mathrm{Cm}$ ); el coeficiente orográfico (Co); el índice de rugosidad (Ir); el coeficiente de mantenimiento $(\mathrm{Cm})$; la extensión del percurso superficial (Eps); la densidad de drenage (Dd) e declividad média. Destacamos también las características de las rocas y su origen y las características topográficas de la cuenca. La análisis de los factores geomorpologicos foi cumplido com la base em datos planialtimétricos de la cuenca, como declividad, hipsometría y también com el uso de Sistema de Información Geográfica (SIG). Las informaciones geomorfológicas y los datos de SIG ayudaron em la determinación de los parámetros morfométricos.
\end{abstract}

Palabras clave: Morfométricos, Conductibilidad, Cuenca hidrográfica.

(*) Doutorando em Geografia pela Universidade Federal de Uberlândia - Universidade Estadual de Goiás (UEG),/ Av. R2, Jardim Novo Horizonte - CEP: 76.200-000 - Iporá (GO), Brasil, Tel. (+55 64) 36031489 - flaueg@hotmail.com

(**) Bolsista Produtividade do CNPq e Prof. Dr. do Instituto de Geografia da Universidade Federal de Uberlândia - Av. Joao Naves de Avila, 2121 - Bloco 1H sala 27, CEP: 38408-100 - Uberlandia (MG), Brasil, Tel: (+55 34) 32394169 - silgel@hotmail.com

MERCAT Mercator, Fortaleza, v. 11, n. 25, p. 141-151, mai./ago. 2012.

ISSN 1984-2201 @ $\quad$ 2002, Universidade Federal do Ceará. Todos os direitos reservados. 


\section{INTRODUÇÃO}

O rio dos Bois é um dos principais afluentes de margem direita do rio Araguaia, tem suas principais nascentes nos municípios de Iporá e Diorama, na região Oeste do Estado de Goiás. Deságua no rio Araguaia no município de Montes Claros de Goiás, depois de percorrer cerca de $200 \mathrm{~km}$. A área de estudo é uma bacia hidrográfica da cabeceira do rio dos Bois, que tem uma área de $10 \mathrm{Km} 2$ e está distante $15 \mathrm{~km}$ do centro de Iporá.

A bacia hidrográfica tem sido uma unidade territorial amplamente trabalhada por pesquisadores das ciências naturais e da terra por ser uma unidade de fácil delimitação, e também por ser possível avaliar vários elementos de seu conjunto. Como um sistema aberto, a troca de energia e matéria se traduz em propulsora da dinâmica da bacia, através das interrelações existentes entre seus diversos elementos.

A morfometria tem ligação direta com a morfologia da bacia, a morfologia por sua vez, apresenta relação direta com a tipologia das formas de relevo, que segundo Ross (1990) "não ocorre de maneira aleatória e caótica", mas apresenta uma ligação direta com os demais componentes do sistema. A morfologia seria então o resultado de combinações diversas dos elementos naturais, onde o embasamento rochoso é a peça principal e os agentes externos, liderados pelos fatores climáticos seriam os responsáveis pela sua esculturação, que nunca se repete de maneira idêntica em dois lugares.

A morfometria por sua vez, seria a geometria do relevo, capaz de ser apreendida e mensurada, e influencia diretamente na dinâmica da bacia, através dos caminhos que obriga a água a fazer, seja ela pluvial ou fluvial. Como as características morfométricas da bacia interferem nos processos de erosão dos solos e na capacidade de infiltração da água, o presente estudo buscou compreender aquelas de maior significância para este tipo de estudo.

A hipsometria é uma variável importante, uma vez que através dela é possível ter uma visão geral do quadro topográfico da bacia, além de que a informação hipsométrica favorece a construção da curva hipsométrica, capaz de demonstrar a configuração do desgaste do relevo. A curva hipsométrica foi proposta como elemento de análise da bacia hidrográfica por Strahler (1952) apud Christofoletti (1980), e tem como objetivo avaliar as condições de desgaste do relevo, ou seja, as áreas mais rebaixadas pela ação dos agentes externos, e as mais preservadas devido à maior resistência dos componentes geológicos.

Outro aspecto considerado neste estudo foi a amplitude altimétrica máxima, proposta por Schumm (1956) apud Christofoletti (1980), que leva em consideração a diferença entre a maior altitude da bacia e a menor altitude, geralmente situada na desembocadura da mesma. SANTA CATARINA (1997) sugere ao definir o ponto de maior altitude, o cálculo da média de pelo menos dez pontos mais elevados situados no divisor da bacia.

Apesar de o relevo apresentar pontos de maior altitude e menor altitude, o desgaste do mesmo não é homogêneo, isso devido à maior ou menor resistência rochosa que compõe o substrato da bacia. Assim a altura média da bacia deverá ser calculada como base para definição de outras variáveis morfométricas. A altura média foi proposta como variável morfométrica por Fournier apud Christofoletti (1980), e é o resultado da relação entre a amplitude altimétrica (Aa) e a integral hipsométrica (Ih), sendo a integral hipsométrica compreendida pela área formada entre a curva hipsométrica, o eixo (y) e o eixo (x).

Também propostos por Fournier apud Christofoletti (1980), os coeficientes orográfico e de massividade representam respectivamente o volume rochoso e a massa rochosa remanescentes numa bacia hidrográfica, e são importantes na definição do grau de resistência das rochas, que por sua vez definem a relação entre erosão e infiltração de água no solo.

Outro parâmetro importante na análise morfométrica da bacia é o índice de rugosidade. Este foi proposto por Melton (1957) apud Christofoletti (1980), como sendo o resultado da relação entre a amplitude altimétrica e a densidade de drenagem. 
Strahler (1958: 1964) apud Epagri (1997, p.29) destaca que:

Se a Dd aumenta enquanto o valor de H permanece constante, a distância horizontal média entre as divisórias e os canais adjacentes será reconduzida, acompanhada de aumento na declividade da vertente. Se o valor de $\mathrm{H}$ aumenta enquanto a Dd permanece constante, também aumentarão as diferenças altimétricas entre o interflúvio e os canais e a declividade das vertentes.

Hott et all (2007) ao analisarem um conjunto de seis bacias hidrográficas mostra que embora a densidade de drenagem seja semelhante entre elas, o índice de rugosidade teve variações significativas em função da variação da amplitude altimétrica.

Considerando que o índice de rugosidade tem influência no processo de infiltração/escoamento superficial, índices fracos a médios favorecem maior infiltração, enquanto índices médios a altos favorecem o escoamento superficial, estimulando eventos erosivos. Todavia não estamos considerando aqui outras variáveis que influenciam no processo, como uso e ocupação das vertentes, conservação da vegetação nativa, constituição rochosa e regime pluviométrico.

Já a densidade de drenagem é segundo Beltrame (1984), a relação entre o comprimento total dos canais de drenagem e a área da bacia. O Quadro 1 abaixo mostra a relação entre o valor da densidade de drenagem e sua intensidade.

Quadro 1 - Classificação dos valores de densidade de drenagem.

\begin{tabular}{|c|c|}
\hline VALOR DA DD $\left(K M / K M^{2}\right)$ & QUALIFICAÇÃO \\
\hline$<0,50$ & Baixa \\
\hline 0,50 a 2,00 & Mediana \\
\hline 2,00 a 3,50 & Alta \\
\hline$>3,50$ & Muito alta \\
\hline
\end{tabular}

O coeficiente de manutenção também é importante para o estudo morfométrico da bacia. Foi proposto por Schumm (1956) apud Christofoletti (1980), indica a área mínima necessária para manutenção de um metro de canal de drenagem.

A extensão do percurso superficial (Eps), que conforme Christofoletti (1980) representa o percurso das enxurradas do interflúvio até o canal de drenagem, interfere na maior ou menor infiltração da água, tendo uma relação direta com a densidade de drenagem.

Dentre os diversos instrumentos de estudo ambiental o mapa de declividades é uma excelente ferramenta, uma vez que proporciona uma visão geral da topografia da área estudada (SOUSA, 2006). Segundo De Biasi (1992), o mapa de declividades tem sido utilizado de maneira quase que obrigatória, em trabalhos ligados às Ciências da Terra, Planejamento Regional, Urbano e Agrário, juntamente com outras representações gráficas de variáveis tais como: orientação de vertentes, insolação direta, direção e velocidade de ventos, entre outras, permitindo, assim, com suas correlações, uma melhor compreensão e um equacionamento dos problemas que ocorrem no espaço analisado.

No estudo das características físicas da bacia hidrográfica é muito importante destacar as características topográficas, principalmente níveis de declividades.

A topografia da bacia é um importante contribuinte através da rugosidade topográfica e da presença de declives acentuados, instáveis. Tem um papel relevante no equilíbrio das encostas sendo um dos fatores da erosão potencial e dos movimentos de massa. (GUERRA E CUNHA, 2003, p. 34).

Todavia é preciso considerar que a dinâmica das vertentes é função dos fatores climáticos, topográficos e de uso da terra.

O conhecimento do substrato geológico também é de fundamental importância no estudo do potencial físico de uma bacia hidrográfica, "e adquire maior importância quando associado à topografia” (GUERRA E CUNHA, 2003, p. 45). 
Dessa maneira o presente estudo buscou avaliar as variáveis aqui descritas com a finalidade de que essas possam subsidiar a compreensão da erodibilidade e da condutividade hidráulica dos solos na bacia hidrográfica.

\section{MATERIAIS E MÉTODOS}

A análise morfométrica teve sua base na delimitação da bacia, o que foi feito com base na carta topográfica de Iporá (SE-22-V-B-III) e imagem de satélite Ikonos (2008). Para a execução de mapas e obtenção de dados necessários aos cálculos da morfometria foi utilizando o software de geoprocessamento Spring 5.0.4 disponível em http://www.dpi.inpe.br/spring/.

\section{Mapa hipsométrico.}

Elaborado com o auxílio de ferramentas de geoprocessamento onde foram utilizadas informações altimétricas vetorizadas retiradas da carta topográfica de Iporá (SE-22-V-B-III), em escala de 1:100.000 e eqüidistância de $50 \mathrm{~m}$.

\section{Curva hipsométrica}

A curva hipsométrica foi elaborada com base na metodologia de Strahler (1952) apud Christofoletti (1980). A representação da curva hipsométrica consiste em um gráfico onde no eixo das ordenadas (Y), foram colocados dados de altimetria. No eixo das abscissas (X), foram colocados dados da área ocupada por cada classe de altitude em porcentagem. A área das classes de altitude foi calculada com base no mapa hipsométrico, com o auxílio da ferramenta operações métricas do Spring.

Através da curva hipsométrica foi possível calcular a integral hipsométrica, que é o resultado da relação entre as áreas relativas de cada um dos intervalos de altitude com a área da bacia (a/A) e das altitudes relativas desses intervalos com a altitude máxima da bacia $(\mathrm{h} / \mathrm{H})$ e, permite avaliar a maturidade da bacia, (ASP, 2009). A integral hipsométrica foi calculada com base em Strahler (1952), conforme a equação abaixo.

$$
\int_{0}^{1} x \cdot d y
$$

Onde: $\mathrm{x}$ corresponde a a/A e y corresponde a $\mathrm{h} / \mathrm{H}$.

\section{Amplitude altimétrica máxima}

Ainda com base nas informações altimétricas da bacia foi definida a amplitude altimétrica máxima. Esta informação foi obtida ao subtrair a altitude mínima da bacia (desembocadura), da altitude máxima em um ponto qualquer do divisor da bacia. Como a altitude máxima pode estar em um único ponto isolado, foi calculada a média dos dez pontos mais elevados para definir o valor do ponto de altitude máxima.

\section{Altura média da bacia}

A altura média (Am) da bacia foi obtida segundo Fournier apud Christofoletti (1980), a altura média é o resultado da relação entre a amplitude altimétrica (Aa) e a integral hipsométrica (Ih), conseguida através de regra de três simples, como mostra a equação abaixo.

$$
\frac{A a}{A m} \times \frac{100}{I h}
$$


Coeficiente orográfico e de massividade.

O coeficiente orográfico $(\mathrm{Co})$ é a representação atual do volume rochoso remanescente numa bacia hidrográfica, resultando da relação entre altura média (Am) e coeficiente de massividade $(\mathrm{Cm})$, foi obtido conforme a equação abaixo.

$$
\mathrm{Co}=\mathrm{Am} . \mathrm{Cm}
$$

O coeficiente de massividade representa a massa rochosa ainda restante na bacia e é foi obtido através do quociente da divisão da altura média pela área da bacia.

$$
C m=\frac{A m}{A}
$$

Índice de rugosidade

Com base no resultado do (Ir) de outras bacias, estabeleceu-se alguns parâmetros para classificar o índice de rugosidade e correlacioná-lo com a forma de relevo, uma vez que tanto a amplitude altimétrica quanto a densidade de drenagem refletem na variação deste índice.

Quadro 2 - Classificação do índice de rugosidade e sua relação com a forma de relevo.

\begin{tabular}{|c|c|l|}
\hline CLASSE DE RUGOSIDADE & VALOR (M) & \multicolumn{1}{|c|}{ FORMA DE RELEVO } \\
\hline Fraca & $0-150$ & Plano com declividade média até a 3\%. \\
\hline Média & $151-550$ & Suave ondulado com declividade média entre 3 e 8\%. \\
\hline Forte & $551-950$ & Ondulado, com declividade média entre 9 e 20\%. \\
\hline Muito Forte & $>950$ & $\begin{array}{l}\text { Forte ondulado a montanhoso a escarpado com declividade média su- } \\
\text { perior a 30\%. }\end{array}$ \\
\hline
\end{tabular}

O índice de rugosidade da bacia foi calculado conforme a equação abaixo.

$$
I r=H . D d
$$

Onde: $\mathrm{Ir}=$ Índice de rugosidade e $\mathrm{Dd}=$ Densidade de drenagem.

\section{Densidade de drenagem}

A densidade de drenagem da bacia foi calculada com o auxílio de ferramentas do SPRING, de onde se obteve as informações de área da bacia e comprimento dos canais, através da ferramenta operações métricas.

$$
D d=\frac{L t}{A}
$$

Onde: $\mathrm{Dd}=$ densidade de drenagem; $\mathrm{Lt}=$ comprimento total dos canais; $\mathrm{A}=$ área da bacia.

\section{Coeficiente de manutenção}

Foi obtido através da equação abaixo:

$$
C m=\frac{1}{\operatorname{Dd} .1000}
$$




\section{Extensão do percurso superficial}

Considerando que a Eps é o quociente da divisão de $1 \mathrm{~km}^{2}$ pelo dobro da densidade de drenagem, é possível estabelecer o grau de intensidade da mesma, com base na escala de qualificação da densidade de drenagem representada no Quadro 3. Dessa maneira poderemos estabelecer as classes de intensidade dos valores de Eps a partir do quociente da divisão de $1 \mathrm{~km} 2$ pelo dobro do valor limite de cada classe de intensidade da densidade de drenagem, chegando aos valores abaixo.

Quadro 3 - Classificação dos valores da extensão do percurso superficial.

\begin{tabular}{|c|c|}
\hline VALORES DA EPS (M) & QUALIFICAÇÃO \\
\hline$>1000$ & Baixa \\
\hline 1000 a 249 & Mediana \\
\hline 248 a 142 & Alta \\
\hline$<142$ & Muito alta \\
\hline
\end{tabular}

A Eps foi obtida conforme a equação a seguir:

$$
\text { Eps }=\frac{1}{2 \cdot \mathrm{Dd}}
$$

Mapa de declividades

Para auxiliar na compreensão dos dados morfométricos foi confeccionado um mapa de declividades da área com uso de ferramentas de geoprocessamento. As classes de declividades foram definidas com o propósito específico de definição dos tipos de relevo, conforme proposta de Lemos \& Santos (1982), ou seja, com intervalos de $0-8 \%$; 9-20\%; $21-45 \%$ e $>45 \%$.

Cálculo da declividade média

A declividade da bacia ajuda na compreensão da dinâmica da infiltração, do escoamento superficial e da erosão dos solos. Por isso, além do mapa de declividades, foi calculada a declividade média da bacia e também a declividade média da porção oeste da bacia, onde se concentra um relevo mais movimentado, para verificar a diferença entre esta porção e o restante da área. Para isso foi calculada a área das duas porções da bacia e medidos os comprimentos totais das curvas de nível em cada setor, através da ferramenta operações métricas do software SPRING.

Para o cálculo da declividade média foi utilizada a equação a seguir, proposta por Carvalho \& Silva (2006).

$$
\mathrm{l} \%=\frac{E}{A} \cdot\left(\sum_{i=1}^{n} \mathrm{CNi}\right) \cdot 100
$$

Onde: $1 \%=$ Declividade média em $\%$;

$\mathrm{E}=$ Equidistância das curvas de nível;

$\mathrm{A}=$ Área da bacia ou seção considerada;

$\mathrm{CNn}=$ comprimento total das $\mathrm{n}$ curvas de nível.

\section{Mapa topomorfológico}

O mapa topomorfológico teve como base os dados altimétricos da bacia e os dados de declividade fornecidos pelo mapa de declividades. Serviu ainda como base de análise o modelo em 3D do relevo da bacia.

\section{RESULTADOS E DISCUSSÕES}

A bacia da alta cabeceira do rio dos Bois ocupa uma área de 10,5 km2. Apresenta um padrão de drenagem dendrítica e um sistema exorréico, ou seja, o conjunto de suas águas tem como ponto 
final o oceano, através de bacias de hierarquia superior, que no presente caso é a bacia hidrográfica do rio Araguaia. Os fatores morfométricos utilizados na análise da bacia estão descritos no Quadro abaixo com seus respectivos resultados.

Quadro 4 - Resumo de fatores morfométricos da bacia hidrográfica na alta cabeceira do Rio dos Bois.

\begin{tabular}{|l|c|c|}
\hline \multicolumn{1}{|c|}{ FATOR } & VALOR & UNIDADE \\
\hline Área & 10,5 & $\mathrm{Km}^{2}$ \\
\hline Altitude Máxima e Mínima & $820-550$ & $\mathrm{~m}$ \\
\hline Amplitude altimétrica (Aa) & 270 & $\mathrm{~m}$ \\
\hline Altura média (Am) & 135 & $\mathrm{~m}$ \\
\hline Coeficiente de massividade (Cm) & 12,8 & $\mathrm{~m} / \mathrm{km}^{2}$ \\
\hline Coeficiente orográfico (Co) & $1.734,75$ & - \\
\hline Índice de rugosidade (Ir) & 380,57 & $\mathrm{~m}$ \\
\hline Coeficiente de manutenção (Cm) & 714,2 & $\mathrm{~m} / \mathrm{km}^{2}$ \\
\hline Extensão do percurso superficial (Eps) & 0,357 & $\mathrm{~km}$ \\
\hline Densidade de Drenagem (Dd) & 1,4 & $\mathrm{Km} / \mathrm{km}^{2}$ \\
\hline Declividade média (leste/oeste) & $8,2-14,31$ & $\%$ \\
\hline
\end{tabular}

Considerando que o volume total do quadrado onde está representada a curva hipsométrica (Figura 1), configura o volume rochoso total e inicial da área, tendo como referência a amplitude altimétrica, foi possível calcular este volume rochoso ainda existente e o que já foi erodido, que é o coeficiente orográfico. Todo espaço contido entre a linha que representa a curva hipsométrica, o eixo $(\mathrm{Y})$ e o eixo $(\mathrm{X})$ representa o volume rochoso ainda existente, também considerada como integral hipsométrica por Strahler (1952).

Com base na altura e na área de cada faixa de altitude calculou-se o volume rochoso da bacia, conforme descrito em SANTA CATARINA (1977). Dessa maneira, 64,25\% da área foram erodidos, embora não seja possível definir o tempo demandado nesse processo. Restam $35,75 \%$ do volume rochoso a ser erodido, o que caracteriza um relevo mediamente dissecado da bacia.

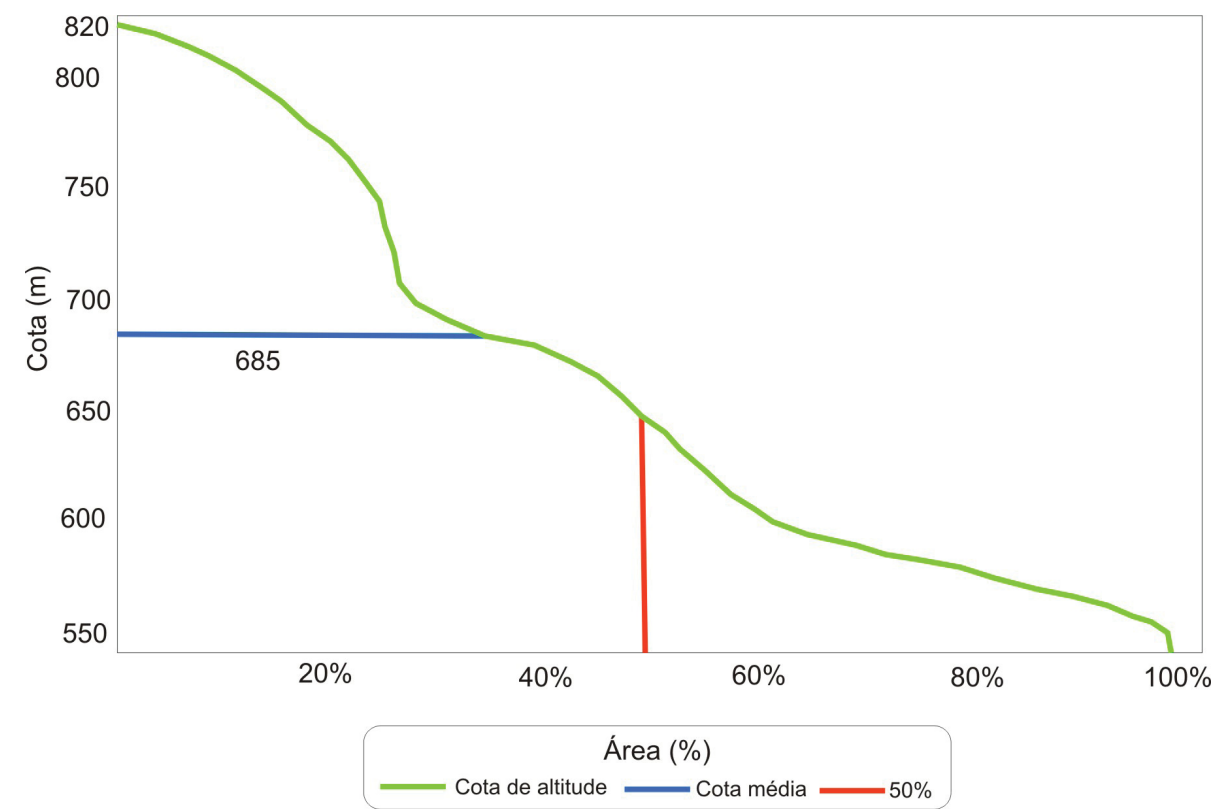

Figura 1 - Curva Hipsométrica da bacia da Alta cabeceira do Rio dos Bois em Iporá-GO. 
A curva hipsométrica é segundo Strahler (1952) uma maneira simplificada de representar o ciclo geomorfológico de uma bacia de drenagem, podendo a mesma caracterizar uma fase jovem do relevo com maiores elevações até uma fase madura, onde o relevo está praticamente aplainado (fase de equilíbrio). O autor destaca ainda uma fase denominada de Monadnock, que seria uma espécie de enclave de um relevo mais acentuado em meio a um relevo em fase adiantada de desgaste. A partir da análise da curva hipsométrica e valor encontrado para a integral hipsométrica $(0,33)$, a bacia se caracteriza numa fase geomorfológica tendendo a madura com características de Monadnock.. Strahler (1952) destaca que na fase efetiva do Monadnock o valor da integral hipsométrica ficaria inferior a 0,35, sedo este o caso da alta bacia do rio dos Bois. $O$ autor destaca ainda que na fase efetiva da maturidade a integral hipsométrica ficaria entre 0,4 e 0,6 .

\section{Extensão do percurso superficial}

A extensão do percurso superficial representa a distância em metros que o fluxo de água do escoamento superficial deverá percorrer até atingir o curso d'água mais próximo. A distância a ser percorrida é tanto maior, quanto menor a declividade da vertente.

$\mathrm{O}$ valor de Eps encontrado para a bacia foi de $357 \mathrm{~m}$, que caracteriza comprimentos de vertentes com valores medianos, ou seja, valores de mediano a baixo favorecem a infiltração, enquanto valores de alto a muito alto favorecem o escoamento superficial.

\section{Índice de Rugosidade}

Este fator caracteriza a relação entre a amplitude altimétrica $(\mathrm{H})$ e a declividade das vertentes, que por sua vez apresenta relação direta com a densidade de drenagem (Dd). Quanto maior a densidade de drenagem, ou a amplitude altimétrica, maior será a rugosidade do terreno, caracterizado por menores comprimentos de rampa e maior declividade, o que acentua o escoamento superficial e também as ocorrências erosivas.

O índice de rugosidade da bacia em questão foi de $380,57 \mathrm{~m}$, sendo classificado como um índice médio, com predominância de relevo suave ondulado, portanto com maior favorabilidade à infiltração.

\section{Coeficiente de manutenção}

Este fator caracteriza a área mínima necessária para que um metro de canal de drenagem seja mantido. Na bacia temos para cada quilômetro quadrado, 7,142 $\mathrm{m}$ de canal de drenagem, comum em bacias de relevo suave ondulado e densidade de drenagem mediana.

\section{Caracterização Geológica}

A bacia em questão está assentada predominantemente sobre rochas cristalinas, predominando o Granito do Tipo Iporá, de idade proterozóica, constituídos por suítes graníticas que exibem corpos de amplas variedades petrográficas, predominando os granitos e os granodioritos pórfiros. Uma pequena área da bacia apresenta litologia Mesozóica/ Cretácea com presença de rochas alcalinas de composições diversas, Dunitos, Peridotitos, Gabros e rochas associadas, (CPRM,1999).

\section{Caracterização topográfica}

Localmente o relevo da sub-bacia é predominantemente suave ondulado a ondulado com altitude variando de 550 a $820 \mathrm{~m}$ e vales em "V" abertos, embora pontualmente se tenha a presença de relevo forte ondulado e escarpado. O grau de entalhamento da drenagem varia de fraco a mediano, com distância interfluvial entre $>250 \mathrm{a} \leq 750 \mathrm{~m}$.

O relevo suave ondulado predomina na maior parte da bacia e também em áreas mais elevadas com relevo de topo plano e declividades variando de 0 a $8 \%$. O relevo ondulado de topo convexo predomina em boa parte da bacia, com declividades variando de 9 a $20 \%$. O relevo Forte ondulado 
predomina em serra residual com declividades variando entre 21 e $45 \%$. Há ainda uma pequena mancha de relevo escarpado em uma pequena ruptura de declive onde a declividade supera os $45 \%$. O Quadro 5 descreve os tipos de relevo presentes na bacia e a área ocupada por cada tipo. A Figura 2 mostra o relevo da bacia em 3D.

Quadro 5 - Tipo de relevo e área ocupada.

\begin{tabular}{|c|c|c|}
\hline TIPO DE RELEVO & ÁREA $\left(\mathrm{KM}^{2}\right)$ & ÁREA EM (\%) \\
\hline Suave ondulado & 5,65 & 53,81 \\
\hline Ondulado & 4,00 & 38,11 \\
\hline Forte Ondulado & 0,82 & 7,80 \\
\hline Montanhoso a escarpado & 0,03 & 0,28 \\
\hline Totais & $\mathbf{1 0 . 5}$ & $\mathbf{1 0 0}$ \\
\hline
\end{tabular}

A Figura.2 mostra uma panorâmica do relevo da bacia.

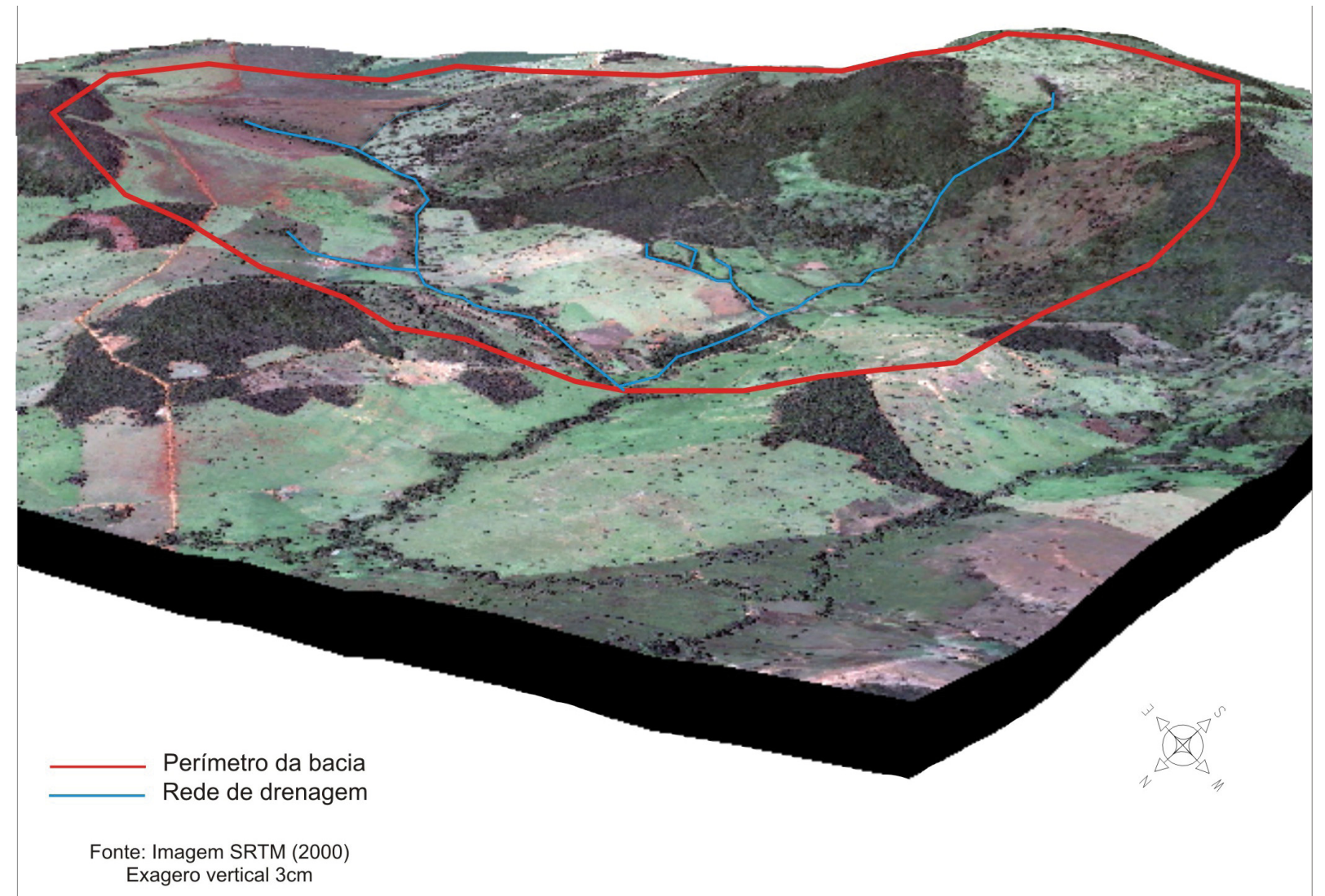

Figura 2 - Visão panorâmica da área da bacia

Considerando os intervalos de declividade adotados na definição dos tipos de relevo foi realizada uma correlação com a suscetibilidade erosiva da bacia a partir dos intervalos de declividades e sua relação com a suscetibilidade erosiva proposta por Ramalho Filho e Beek (1995) através de agrupamento das classes de suscetibilidade, uma vez que os intervalos definidos pelos autores são: $0-3 \% ; 3-8 \% ; 8-13 \% ; 13-20 \% ; 20-45 \%$ e $>45 \%$. 
SOUSA, F. A.; RODRIGUES, S. C.

Quadro 6 - Associação do relevo com a declividade e o grau de suscetibilidade erosiva.

\begin{tabular}{|c|c|c|}
\hline TIPO DE RELEVO & CLASSES DE DECLIVIDADES & $\begin{array}{c}\text { SUSCETIBILIDADE EROSI- } \\
\text { VA ASSOCIADA }\end{array}$ \\
\hline Suave ondulado & $0-8 \%$ & Não suscetível a pouco suscetível. \\
\hline Ondulado & $9-20 \%$ & Moderada a Forte. \\
\hline Forte Ondulado & $21-45 \%$ & Muito Forte. \\
\hline Montanhoso a escarpado & $>45 \%$ & Severa \\
\hline
\end{tabular}

Fonte: Adaptado de Ramalho Filho e Beek (1995).

Com base na declividade média calculada para a parte mais rebaixada da bacia, obteve-se valor de $8,2 \%$, portanto dentro do intervalo de pouca suscetibilidade erosiva. A parte mais elevada apresentou declividade média de 14,31\%., considerada uma declividade que favorece uma suscetibilidade erosiva forte, conforme a classificação de Ramalho Filho e Beek (1995).

Avaliando as formas de relevo e a declividade média da bacia foi possível perceber que há uma proporcionalidade entre a área mais elevada e a mais rebaixada, ou seja, 46,19\% da área da bacia apresentam relevo que varia de ondulado a escarpado e declividade média que favorece uma suscetibilidade erosiva forte, e também uma maior tendência ao escoamento superficial. A parte mais rebaixada $(53,81 \%)$ apresenta relevo suave ondulado e tendência a pouca suscetibilidade erosiva, que em tese favorece a infiltração.

Os resultados obtidos neste estudo parcial serão correlacionados com experimentos de campo e laboratório, considerando aspectos como o comportamento da infiltração, características físicas dos solos, natureza da base litológica, balanço hídrico e comportamento do nível freático.

\section{CONSIDERAÇÕES FINAIS}

A análise morfométrica é muito importante no auxílio ao planejamento ambiental e na compreensão de fatores causadores de erosão e na dinâmica da água de infiltração, pois facilita o diagnóstico da área e favorece a escolha dos melhores locais para realização de experimentos. Cabe ressaltar que os fatores morfométricos podem ser correlacionados com outros fatores específicos da bacia hidrográfica, conforme for o objetivo e a natureza do estudo.

Os subsídios dados pelas análises realizadas foram principalmente na escolha de locais (pontos), mais adequados para a realização dos experimentos de infiltração e coleta de amostras de solos; no entendimento do relevo e na sua aptidão para a infiltração e no diagnóstico de eventos erosivos. Foi possível perceber que do ponto de vista da morfometria da bacia apenas a metade da área contribui com o processo de infiltração da água no solo, mas cuja eficiência só poderá ser descrita com base nos experimentos de infiltração a serem ainda realizados.

No presente caso, analisamos apenas aqueles fatores que poderiam auxiliar de maneira mais direta na compreensão da dinâmica da água de infiltração e na localização de pontos mais suscetíveis aos eventos erosivos, sem esquecer que a análise de outros fatores físicos da bacia e o emprego de experimentos específicos é que comporão o quadro geral pretendido.

\section{REFERÊNCIA BIBLIOGRÁFICA}

BELTRAME, Ângela da Veiga. Diagnóstico do Meio físico de Bacias hidrográficas: modelo e aplicações. Florianópolis: Ed. da UFSC, 1994.

CARVALHO, D. F. de \& SILVA, L. D. B. Hidrologia: Bacia Hidrográfica, 2006. Disponível em: www.ufrrj. br/institutos/it/deng/leonardo/.../HIDRO-Cap3-BH.pdf. Acesso em: 12/02/2011. 
CHRISTOFOLETTI, A. Geomorfologia. 2a . ed., São Paulo: Edgard Blucher, 1980.

CPRM/MME. Programa Levantamentos Geológicos Básicos do Brasil. Folha SE-22 (Iporá). Luiz Carlos Moreton (org.). Brasília, 1999.

DE BIASI, Mário. A carta clinográfica: os métodos de representação e sua confecção. Revista de Geografia. São Paulo: USP, 1992.

GUERRA, J. T. \& CUNHA, S. B. da. - Degradação Ambiental. In: Geomorfologia e Meio Ambiente. Rio de janeiro: Bertrand Brasil, 2003.

HOTT, M. C.; FURTADO, A. L. S. RIBEIRO, C. A. A. S. - Determinação automática de parâmetros morfométricos de bacias hidrográficas no município de Campinas - SP. In: Anais XIII Simpósio Brasileiro de Sensoriamento Remoto, Florianópolis, Brasil, 21-26 abril 2007, INPE, p. 3381-3388.

LEMOS, R. C.; SANTOS, R. D dos. Manual de descrição e coleta de solo no campo. $2^{\mathrm{a}}$ Ed. Campinas: SBPG - SNLCS, 1982.

ROSS, J. L. S. Geomorfologia: Ambiente e Planejamento. São Paulo: Contexto, 1990.

SANTA CATARINA. Secretaria de Estado do Desenvolvimento Urbano e Meio Ambiente. Secretaria de Estado do Desenvolvimento Rural e Agricultura. Plano de Gestão e geenciamento da bacia do rio Ararangua - zoneamento da disponibilidade e qualidade hídrica. Elaboração: Epagri: Gerência Regional da E.E. de Urussanga/SC. Florianópolis, 1997.

SOUSA, F. A. de. Uso e ocupação na bacia hidrográfica do ribeirão Santo Antônio em Iporá-Go.,como subsídio ao planejamento (Dissertação de Mestrado). Goiânia: IESA/UFG, 2006.

RAMALHO FILHO, A. \& BEEK, K. J. Sistema de avaliação da aptidão agrícola das terras. $3^{\text {a }}$. edição. Rio de janeiro: EMBRAPA- CNPS, 1995.

Trabalho enviado em novembro de 2011

Trabalho aceito em dezembro de 2011 